\title{
BROOKHFUEN
}

NATIONAL LABORATORY

BNL-75362-2006-IR

\section{Polyethersulfone Coating for Mitigating Corrosion of Steel in Geothermal Environment}

\author{
Toshifumi Sugama
}

June 2005

\author{
Energy Sciences and Technology Department \\ Energy Resources Division \\ Brookhaven National Laboratory \\ P.O. Box 5000 \\ Upton, NY 11973-5000 \\ www.bnl.gov
}

\footnotetext{
Notice: This manuscript has been authored by employees of Brookhaven Science Associates, LLC under Contract No. DE-AC02-98CH10886 with the U.S. Department of Energy. The publisher by accepting the manuscript for publication acknowledges that the United States Government retains a non-exclusive, paid-up, irrevocable, world-wide license to publish or reproduce the published form of this manuscript, or allow others to do so, for United States Government purposes.
} 


\section{DISCLAIMER}

This report was prepared as an account of work sponsored by an agency of the United States Government. Neither the United States Government nor any agency thereof, nor any of their employees, nor any of their contractors, subcontractors, or their employees, makes any warranty, express or implied, or assumes any legal liability or responsibility for the accuracy, completeness, or any third party's use or the results of such use of any information, apparatus, product, or process disclosed, or represents that its use would not infringe privately owned rights. Reference herein to any specific commercial product, process, or service by trade name, trademark, manufacturer, or otherwise, does not necessarily constitute or imply its endorsement, recommendation, or favoring by the United States Government or any agency thereof or its contractors or subcontractors. The views and opinions of authors expressed herein do not necessarily state or reflect those of the United States Government or any agency thereof. 


\begin{abstract}
Emphasis was directed toward evaluating the usefulness of a polyethersulfone (PES)-dissolved N-methyl pyrrolidone (NMP) solvent precursor as a low-temperature film-forming anti-corrosion coating for carbon steel in simulated geothermal environments at brine temperatures up to $300^{\circ} \mathrm{C}$. A $\sim 75 \mu \mathrm{m}$ thick PES coating performed well in protecting the steel against corrosion in brine at $200^{\circ} \mathrm{C}$. However, at $\geq 250^{\circ} \mathrm{C}$, the PES underwent severe hydrothermal oxidation that caused the cleavage of sulfone- and ether-linkages, and the opening of phenyl rings. These, in turn, led to sulfone $\rightarrow$ benzosulfonic acid and ether $\rightarrow$ benzophenol-type oxidation derivative transformations, and the formation of carbonyl-attached open rings, thereby resulting in the incorporation of the functional groups, hydroxyl and carbonyl, into the coating. The presence of these functional groups raised concerns about the diminutions in water-shedding and -repellent properties that are important properties of the anti-corrosion coatings; such changes were reflected in an enhancement of the magnitude of susceptibility of the coatings' surfaces to moisture. Consequently, the disintegration of the PES structure by hydrothermal oxidation was detrimental to the maximum efficacy of the coating in protecting the steel against corrosion, allowing the corrosive electrolytes to infiltrate easily through it.
\end{abstract}




\section{Introduction}

Cost-effective anti-corrosion and anti-fouling coatings for carbon steel components in the geothermal power plants operating at brine temperatures up to $250^{\circ} \mathrm{C}$, play an important role in decreasing capital investment and the expenses of operation and maintenance, leading to eventually a lowering of the cost of the electricity generated from plants.

Some specific plant components, such as the heat exchanger unit and long pipeline, require joints to complete them. The roller expansion and welding jointing processes are among the most popular ways to make the heat exchanger (HX) tubes-totube sheet joints, and also the pipe-to- pipe joints. In the former process, the thickness of the wall of the carbon steel HX tubes are reduced by $\sim 6 \%$ reduction as they are rolled into a tube sheet. Consequently, none of coatings can withstand such high compressive strength and abrasive wear during this expansion. Likewise, welding at high temperature causes thermal decomposition of the coatings: Hence, the joint areas of $\sim 10.0 \mathrm{~cm}$ wide, must be recoated in the factories or fields with materials possessing the following four properties: 1) able to cure well at temperatures up to $100^{\circ} \mathrm{C}$;2) hydrothermal stability of $>200^{\circ} \mathrm{C}$; 3) good adherence to the joint areas; and, 4) be suitable for application with a paintbrush or spray gun.

Among the high-performance polyaryl-based engineering polymers, polyethersuflone (PES) is known to possess excellent thermal properties including the deflection temperature of $200^{\circ} \mathrm{C}$ under a pressure of $1.8 \mathrm{MPa}$, a high glass transition temperature of $\sim 230^{\circ} \mathrm{C}$, and processing temperature of $\sim 320^{\circ} \mathrm{C}$ [1]. Although it is well documented that exposure to UV radiation causes photo-degradation of the PES film [2,3], two critical factors, its stability at high temperature and its solubility in an organic solvent at relatively low temperature of $90^{\circ} \mathrm{C}$, urged us to evaluate its potential as a lowtemperature curable, corrosion-preventing coating for the joint areas in a hot brine environment. Therefore, the factors evaluated in this study included the conductivity of corrosive ions through the films before and after exposure in an autoclave at temperatures up to $300^{\circ} \mathrm{C}$, the water-wetting behaviors of films' surfaces before and after exposure, and the changes in chemical state of the films' surfaces as a function of exposure temperature. 


\section{Experimental procedures}

Solvay Advanced Polymers, LLC., supplied the polyethersulfone (PES) amorphous polymer as a powder. The $\mathrm{N}$-methyl pyrrolidone (NMP) solvent used to dissolve the PES was obtained from Lyondell Chemical Corp. Assuming that the surface of joint areas is prepared by sand blasting, the sand blasted 1010 carbon steel coupons, $6.5 \mathrm{~cm} \times 6.5 \mathrm{~cm}$, were employed as the substrates. The PES powder was dissolved in the NMP solvent at $100^{\circ} \mathrm{C}$, and the precursor solution was left for 24 hours in an ambient temperature before using it. Four formulations were prepared as the solvent-based coatings with PES/NMP weight ratios of 5/95, 10/90, 15/85, and 20/80. The surfaces of the coupons were coated with a PES-dissolved NMP solution using a paintbrush, and then left for 24 hours at ambient temperature to allow most of the NMP to evaporate; after this time, the PES solution covering the surfaces of the metal had become converted into a solid film. To ensure that these coatings did not retain any NMP solvent, the PEScoated steel panels were heated for 10 hours in an air oven at $100^{\circ} \mathrm{C}$. This coating process was repeated four times to make films $\sim 25 \mu \mathrm{m}$ thick for the $5 / 95$ ratio, $\sim 48 \mu \mathrm{m}$ for the $10 / 90$ ratio, $\sim 74 \mu \mathrm{m}$ for the $15 / 85$ ratio, and $\sim 100 \mu \mathrm{m}$ for the $20 / 80$ ratio. The coated coupons were exposed for up to 15 days in an autoclave containing a $\mathrm{CO}_{2}$-laden brine ( $0.5 \mathrm{wt}$ \% sodium hydrogen carbonate, $13 \mathrm{wt} \%$ sodium chloride, and $86.5 \mathrm{wt} \%$ water) at $200^{\circ}, 250^{\circ}$, and $300^{\circ} \mathrm{C}$.

$\mathrm{AC}$ electrochemical impedance spectroscopy (EIS) was employed to evaluate the ability of the exposed coating films to protect the steel from corrosion. The specimens were mounted in a holder, and then inserted into an electrochemical cell. Computer programs were prepared to calculate theoretical impedance spectra and to analyze the experimental data. Specimens with a surface area of $13 \mathrm{~cm}^{2}$ were exposed to an aerated $0.5 \mathrm{M}$ sodium chloride electrolyte at $25^{\circ} \mathrm{C}$, and single-sine technology with an input $\mathrm{AC}$ voltage of $10 \mathrm{mV}$ (rms) was employed over a frequency range of $10 \mathrm{KHz}$ to $10^{-2} \mathrm{~Hz}$. To estimate the protective performance of the coatings, the pore resistance, $\mathrm{Rp}$, $\left(\mathrm{ohm}-\mathrm{cm}^{2}\right)$ was determined from the plateau in Bode-plot scans that occurred in low frequency regions. The extent of water repellency and susceptibility to moisture of the exposed coatings' surfaces was estimated by measuring the contact angle within the first 
30 seconds after releasing a water droplet on their surfaces. This information was supported by X-ray photoelectron spectroscopy.(XPS) analysis that provides data on the degree of hydrothermal oxidation of the exposed coatings' surfaces as well as identifying the chemical states formed at their outermost surface sites.

\section{Results and discussion}

Figure 1 compares the Bode-plot features [the absolute value of impedance $|\mathrm{Z}|\left(\mathrm{ohm}-\mathrm{cm}^{2}\right)$ vs. frequency $\left.(\mathrm{Hz})\right]$ of the uncoated coupons and those coated with 5,10 , 15 , and $20 \%$ PES solutions. Particular attention in the overall EIS curve was given to the $\mathrm{Rp}$, which can be determined from the peak in the Bode-plot occurring at sufficiently low frequency between $10^{-1}$ and $10^{-2} \mathrm{~Hz}$. For the uncoated steel coupon, the Rp value was 4.5 $\mathrm{x} 10 \mathrm{ohm}-\mathrm{cm}^{2}$. For coupons coated with the $5 \% \mathrm{PES}$, the Rp value rose more than two orders of magnitude to $8.5 \times 10^{3} \mathrm{ohm}-\mathrm{cm}^{2}$ compared with that of the uncoated one. A further increase to $1.1 \times 10^{5} \mathrm{ohm}-\mathrm{cm}^{2}$ was observed from the $10 \%$ PES-coated coupon, while the one with $15 \%$ PES had the highest Rp value of $2.0 \times 10^{5} \mathrm{ohm}-\mathrm{cm}^{2}$. In contrast, the $20 \%$ PES coating with the thickest film, $100 \mu \mathrm{m}$, was not as effective in increasing the $R p$ value as were the 10 and $15 \%$ PES coatings; its value of $2.8 \times 10^{4} \mathrm{ohm}-\mathrm{cm}^{2}$ was one order of magnitude lower than that of the 10 and $15 \%$ PES coatings. A possible reason for this was the fact that the viscosity of $20 \% \mathrm{PES}$ solution was too high to obtain a uniform cover over the entire coupon's surface by painting it on with a brush. Some air spaces at interfaces between the coupon's surface and solution develop during the coating process. Indeed, the $20 \%$ PES solution-derived coating was locally delaminated from the substrate surfaces after leaving it at room temperature for 24 hours. Since the Rp value reflects the magnitude of ionic conductivity generated by the $\mathrm{NaCl}$ electrolyte passing through the coating layers, such a reduced value signified that the uptake of electrolytes by the coating was enhanced as more PES was added to the NMP solvent. Thus, $15 \%$ was the most effective concentration of PES in minimizing the uptake of corrosive electrolytes by the coating.

Further studies centered on obtaining information on the ability of the $15 \%$ PESderived coating to protect the steel against corrosion after exposure to hot $\mathrm{CO}_{2}$-laden brine at $200^{\circ}, 250^{\circ}$, and $300^{\circ} \mathrm{C}$. There were no further investigations of 5,10 , and $20 \%$ 
PES. The first approach to obtaining this information was to survey whether the exposed coatings' surfaces still retain their hydrophobic characteristic, i.e., are minimally susceptible to moisture. This characteristic is among the indispensable factors for good protective coatings. To gain this information, the extent of water repellency and shedding of the coatings' surfaces was estimated from the changes in contact angle made by a water droplet on the coatings' surfaces before and after exposure to heated brine. If the contact angle declines after exposure, the coating surfaces were judged to be becoming a susceptible to moisture; a high degree of susceptibility may allow moisture to permeate through the coatings easily. Figure 2 plots the average value of contact angle, $\theta$, (degree), for five water droplets over the coatings' surfaces as a function of exposure time at autoclave temperatures of $200^{\circ}, 250^{\circ}$, and $300^{\circ} \mathrm{C}$. The $\theta$ value of unexposed coating was $80.7^{\circ}$, and its value declined with an increase in exposure time at these temperatures. - However, the magnitude of this decrease depended on the temperature; in particular, its value markedly fell as the coatings were autoclaved for 15 days at $250^{\circ}$ and $300^{\circ} \mathrm{C}$, corresponding to reductions of as much as 39.4 and $53.5 \%$ to $48.9^{\circ}$ and $37.5^{\circ}$, respectively. In contrast, at $200^{\circ} \mathrm{C}$, the rate of reduction was only a $17.7 \%$ after 15 days exposure. Apparently, the surfaces of coatings autoclaved at $250^{\circ}$ and $300^{\circ} \mathrm{C}$ became much more susceptible to moisture than those exposed to $200^{\circ} \mathrm{C}$.

In trying to explicate the reasons why the sensitivity to moisture of the $250^{\circ} \mathrm{C}$ and $300^{\circ} \mathrm{C}$-autoclaved coating surfaces was so enhanced, focus concentrated on investigating two factors, hydrothermal oxidation, and the chemical states at outermost surface sites of unexposed and exposed coatings using XPS. All XPS inspections were made at an electron take-off angle of $40^{\circ}$, which corresponds to an electron-penetration depth of $\sim 5.0 \mathrm{~nm}$. Figure 3 depicts the changes in the XPS O/C atomic ratio of $200^{\circ}$, $250^{\circ}$-, and $300^{\circ} \mathrm{C}$-autocalved coatings' surfaces as function of exposure time. At $200^{\circ} \mathrm{C}$, the $\mathrm{O} / \mathrm{C}$ ratio gradually increased as the exposure time was extended. After 15 days, the $\mathrm{O} / \mathrm{C}$ ratio of 0.28 was $12 \%$ higher that that of the unexposed coating, suggesting that the some oxygen had been incorporated into the superficial layer ( $\sim 5.0 \mathrm{~nm}$ thickness) of coating. In contrast, its ratio in the $250^{\circ}$ and $300^{\circ} \mathrm{C}$-autoclaved coatings was much higher, underscoring the fact that their surfaces underwent notable hydrothermal oxidation. Interestingly, the ratio in the $300^{\circ} \mathrm{C}$ coating strikingly increased as the exposure time was 
prolonged, but then it leveled off at 10 days, implying that hydrothermal oxidation of the superficial layer was completed in the first 10 days of exposure at $300^{\circ} \mathrm{C}$.

Attention next shifted to identifying the surface oxidation products formed after autoclaving. This information was obtained by inspecting the XPS $S_{2 p}$ and $\mathrm{C}_{1 \mathrm{~s}}$ core-level spectra of the coatings' surfaces before and after autoclaving for 15 days at $200^{\circ}, 250^{\circ}$, and $300^{\circ} \mathrm{C}$ (Figure 4). In these spectra, the scale of the binding energy (BE) was fixed by carbon peak at $285.0 \mathrm{eV}$ as an internal reference standard. A curve deconvolution technique was employed to substantiate the information on the sulfur and carbon-related chemical states from the spectrum of the sulfur and carbon atoms.

In the $S_{2 p}$ region, the spectrum for unexposed coating can be deconvoluted by two resolvable Gaussian components at the $\mathrm{BE}$ positions of $168.2 \mathrm{eV}$ as the principal peak and of $169.3 \mathrm{eV}$ as the shoulder peak. An XPS study on sulfur-oxygen bonds [4] suggested that the increase in the rate of oxidation of $S$ results in a shift in peak position to a high $\mathrm{BE}$ side; for instance, sulfoxide $(>\mathrm{S}=\mathrm{O})$ around $165.9 \mathrm{eV}$, sulfone $\left(-\mathrm{SO}_{2^{-}}\right)$at $168.0 \mathrm{eV}$, sulfonic acid $\left(-\mathrm{SO}_{3} \mathrm{H}\right)$ at $\sim 169: 0 \mathrm{eV}$, and sulfate $\left(-\mathrm{SO}_{4}\right)$ at $\sim 169.8 \mathrm{eV}$. From this information, the contributor at $168.2 \mathrm{eV}$ is the $\mathrm{S}$ originating from the sulfone bridging groups, which link the phenyl rings in the PES structure, and at $169.8 \mathrm{eV}$, the $\mathrm{S}$ comes from the sulfonic acid group as the minor component. When this coating was autoclaved at $200^{\circ} \mathrm{C}$, a new signal emerged in the spectrum at $170.4 \mathrm{eV}$, while the signal intensity at $169.3 \mathrm{eV}$ increased somewhat. A possible contributor to this new signal is the $\mathrm{S}$ in the sulfate group-associated compounds. Increasing the temperature to $250^{\circ} \mathrm{C}$ resulted in a striking growth of the sulfonic acid group-related peak at $169.3 \mathrm{eV}$, along with a further increase in intensity of sulfate group signal at $170.4 \mathrm{eV}$. Meanwhile, the strong signal from bridging sulfones at $168.2 \mathrm{eV}$ revealed that this group is still the principal component. The spectral features of the $300^{\circ} \mathrm{C}$-autoclaved coating differed from those at $250^{\circ} \mathrm{C}$; in particular, there were three changes: (1) the sulfonic acid signal became the principal peak, representing the major chemical component; (2) the sulfate signal became more visible; and, (3) the intensity of sulfone signal conspicuously decayed.

In the $\mathrm{C}_{1 s}$ region, the spectrum of unexposed coating surfaces included three Gaussian components at $285.0,286.5$, and $291.8 \mathrm{eV}$, revealing the $\mathrm{C}$ originating from the 
hydrocarbon, $\mathrm{CH}_{n}$, in the phenyl rings, the ether, $\mathrm{C}-\mathrm{O}-\mathrm{C}$, linkages, and the $\pi \rightarrow \pi^{*}$ shakeup satellite of conjugated $\mathrm{C}=\mathrm{C}$ bonds in the phenyl rings, respectively [5]. Similar spectral features were observed from the $200^{\circ} \mathrm{C}$-autoclaved coating surfaces. In contrast, autoclaving at $250^{\circ} \mathrm{C}$ resulted in a new signal at $287.6 \mathrm{eV}$, assignable to the $\mathrm{C}$ in carbonyl, $\mathrm{C}=\mathrm{O}$, group; it also led to the attenuation of the $\pi \rightarrow \pi^{*}$ shake-up peak at 291.8 $\mathrm{eV}$. Raising the temperature further to $300^{\circ} \mathrm{C}$ eliminated the $\pi \rightarrow \pi^{*}$ shake-up peak, while the signal from the $\mathrm{C}=\mathrm{O}$ group intensified; the signal intensity at $286.5 \mathrm{eV}$ also notably increased. A possible interpretation for this elimination is that the phenyl rings underwent a severe hydrothermal oxidation at $300^{\circ} \mathrm{C}$, severing their $\mathrm{C}=\mathrm{C}$ bonds, and resulting in their opening.

In previous studies by several investigators on the thermal- and photo-oxidation degradation pathways of PES and polysulfone [6,7], the first step in their degradation was identified as the cleavage of C-S bonds in the bridging sulfone linkages to form the benzosulfone radicals, $\mathrm{R}_{-} \mathrm{SO}_{2} \cdot$. These radicals then were quenched by oxygen, thereby forming benzosulfone peroxy radicals, $\mathrm{R}-\mathrm{SO}_{2} \mathrm{OO}$. Meanwhile, the oxidation of the phenyl rings promoted the rupture of $\mathrm{C}-\mathrm{H}$ and $\mathrm{C}-\mathrm{C}$ bonds in the rings, resulting in the opening of the rings, as well as yielding oxidized carbon derivatives. Afterwards, the benzosulfone peroxy radicals abstract hydrogen from the ruptured C-H bonds to form benzosulfone hydroperoxide, $\mathrm{R}-\mathrm{SO}_{2} \mathrm{OOH}$, as the intermediate product. Decomposition of this hydroperoxide generated benzosulfonic acid, $\mathrm{R}-\mathrm{SO}_{2} \mathrm{OH}$, as the oxidation product. In addition, oxidation also brought about the breakage of $\mathrm{O}-\mathrm{C}$ bonds in the ether linkage, followed by hydrogen abstraction, and led to the formation of benzophenol-type derivatives.

Relating these previous studies to this XPS result, it appeared that the bridging sulfone linkages were transformed into benzosulfonic acid as the hydrothermal oxidation product during exposure in hot brine. Such sulfone $\rightarrow$ benzosulfonic acid conformational transformation was increasingly enhanced by raising the temperature of the brine from $200^{\circ}$ to $300^{\circ} \mathrm{C}$. Especially, at $\geq 250^{\circ} \mathrm{C}$, the phenyl rings underwent severe hydrothermal oxidation, causing the rupture of $\mathrm{C}-\mathrm{H}, \mathrm{C}=\mathrm{C}$, and $\mathrm{C}-\mathrm{C}$ bonds in the rings along with their subsequent opening. Additionally, these bond breakages led to the incorporation of the $\mathrm{C}=\mathrm{O}$ groups as the oxidation reaction product into the opened rings. The $\mathrm{SO}_{4}$ groups 
detected in this study may be due to the formation of intermediate benzosulfone hydroperoxide, $\mathrm{R}-\mathrm{SO}_{2} \mathrm{OOH}$; which is converted eventually into benzosulfonic acid. On the other hand, the marked increase in the peak intensity at $286.5 \mathrm{eV}$ for the $300^{\circ} \mathrm{C}$ autoclaved coating can be taken as evidence that the scission of a substantial number of ether linkages took placed at $300^{\circ} \mathrm{C}$, reflecting the formation of benzophenol-type oxidation derivatives because the signal at $286.5 \mathrm{eV}$ not only is attributed to the $\mathrm{C}$ in the ether linkages, but also to the $\mathrm{C}$ linked to hydroxyl. If this interpretation is valid, hydrothermal oxidation of the PES coating surfaces can be illustrated as follows:

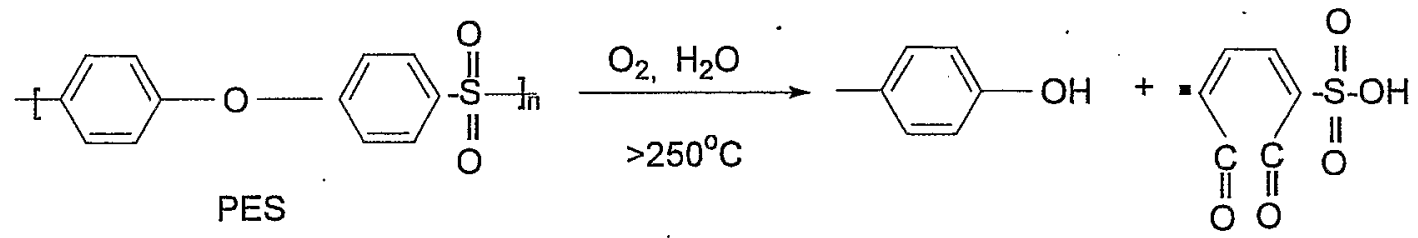

As seen in this scheme, these oxidation derivatives included two functional groups, hydroxyl and carbonyl. Thus, the incorporation of these functional groups into the superficial layer of coating is the reason why the $250^{\circ}$ and $300^{\circ} \mathrm{C}$-autoclaved coatings' surfaces became very susceptible to moisture.

All the information described above was directly correlated with the ability of $200^{\circ}, 25^{\circ} 0^{\circ}$, and $300^{\circ} \mathrm{C}$-autoclaved PES coatings to protect the carbon steel against corrosion. Again, the EIS was used to gain this information. Figure 5 plots the value of pore resistance, $\mathrm{Rp}$, obtained from the EIS curve for the autoclaved coatings versus the exposure time. The data clearly verified that during the first 5 daysof autoclaving the coatings at $250^{\circ}$ and $300^{\circ} \mathrm{C}$, their maximum efficacy as corrosion-preventing barrier layer diminished considerably. In fact, the Rp values of $9.6 \times 10^{3}$ and $6.3 \times 10^{3} \mathrm{ohm}-\mathrm{cm}^{2}$ for 5 day autoclaved coatings at $250^{\circ}$ and $300^{\circ} \mathrm{C}$, respectively, were more than one order of magnitude lower than that of the unexposed coating, underscoring that the autoclaved coatings allowed the corrosive electrolytes to permeate easily through their layers. Beyond 5 days, the values gradually declined with an increase in exposure times up to 15 
days. In contrast, although the $\mathrm{Rp}$ value at $200^{\circ} \mathrm{C}$ tended to decrease with extending exposure time, the rate of its decrease was much lower that those at $250^{\circ}$ and $300^{\circ} \mathrm{C}$. A $2.9 \times 10^{4} \mathrm{ohm}-\mathrm{cm}^{2}$ for 15 -day exposed coating at $200^{\circ} \mathrm{C}$ was nearly one order of magnitude higher than those of $250^{\circ}$ and $300^{\circ} \mathrm{C}$-autoclaved coatings exposed for the same time. It appears that in a $200^{\circ} \mathrm{C}$ environment, the coating displays more resistance to attack by the brine than at $250^{\circ}$ and $300^{\circ} \mathrm{C}$.

\section{Conclusions}

Among a series of amorphous polyethersulfone (PES) polymer-dissolved Nmethyl pyrrolidone (NMP) solvent precursor systems, one consisting of $15 \mathrm{wt} \%$ PES and $85 \mathrm{wt} \%$ NMP proved to be the most effective in fabricating a coating film for protecting carbons steel against corrosion. When the PES films were exposed in brine at $200^{\circ}, 250^{\circ}$, and $300^{\circ} \mathrm{C}$, their surfaces underwent hydrothermal oxidation. At $200^{\circ} \mathrm{C}$, the incorporation of some oxygen into the PES structure led to the rupture of sulfone linkages within PES, causing the formation of intermediate benzosulfone hydroperoxide, which was converted eventually into benzosulfonic acid as the oxidation derivative. Increasing the brine temperature to $250^{\circ} \mathrm{C}$ that incorporated more oxygen, not only markedly promoted the sulfone $\rightarrow$ benzosulfonic acid conformational transformation, but also brought about the scissure of $\mathrm{C}-\mathrm{C}, \mathrm{C}=\mathrm{C}$, and $\mathrm{C}-\mathrm{H}$ bonds in the phenyl rings, thereby resulting in their opening. In addition, a substantial number of the ether linkages within PES were broken as the temperature was further increased to $300^{\circ} \mathrm{C}$. This breakage promoted the ether $\rightarrow$ benzophenol-type oxidation derivative transformation, while the two other oxidationassociated conformational changes, sulfone $\rightarrow$ benzosulfonic acid and ring opening, still continued. In considering the corrosion-preventing performance of coatings, the considerable attention must be paid to these oxidation derivatives and to ring opening that generates the functional hydroxyl and carbonyl groups because they both enhance the magnitude of susceptibility of the coatings' surfaces to moisture. Thus, in a $200^{\circ} \mathrm{C}$ brine environment, PES coating of $\sim 74 \mu \mathrm{m}$ thick adequately protected the carbon steel against corrosion because of minimum hydrothermal oxidation. In contrast, at $\geq 250^{\circ} \mathrm{C}$, the 
maximum efficacy of the coatings in preventing the corrosion was significantly diminished by their severe oxidation.

\section{References}

[1] H. Ulrich, "Introduction to Industrial Polymers", Palmertone Publishing Corp., New York, 1974, p. 153.

[2] J. Peeling, J. Appl. Polym. Sci. 26 (1981) 3761.

[3] L.H. Perng, Polym. Degrad. Stab. 69 (2000) 323.

[4] B.J. Lindherg, K. Hamrin, G. Johansson, U. Gelius, A. Fahlman, C. Nordling and K. Siegbahn, Physical Scipta 1 (1970) 286.

[5] D. Briggs, D.M. Brewis and M.B. Konioeczko, J. Mater. Sci. 14 (1979) 1344.

[6] B.D. Gesner and P.G. Kelleher, J. Appl. Polym. Sci. 12 (1968) 1199.

[7] A. Rivaton and J.L. Gardette, Polym. Degrad. Stab. 66 (1999) 385. 


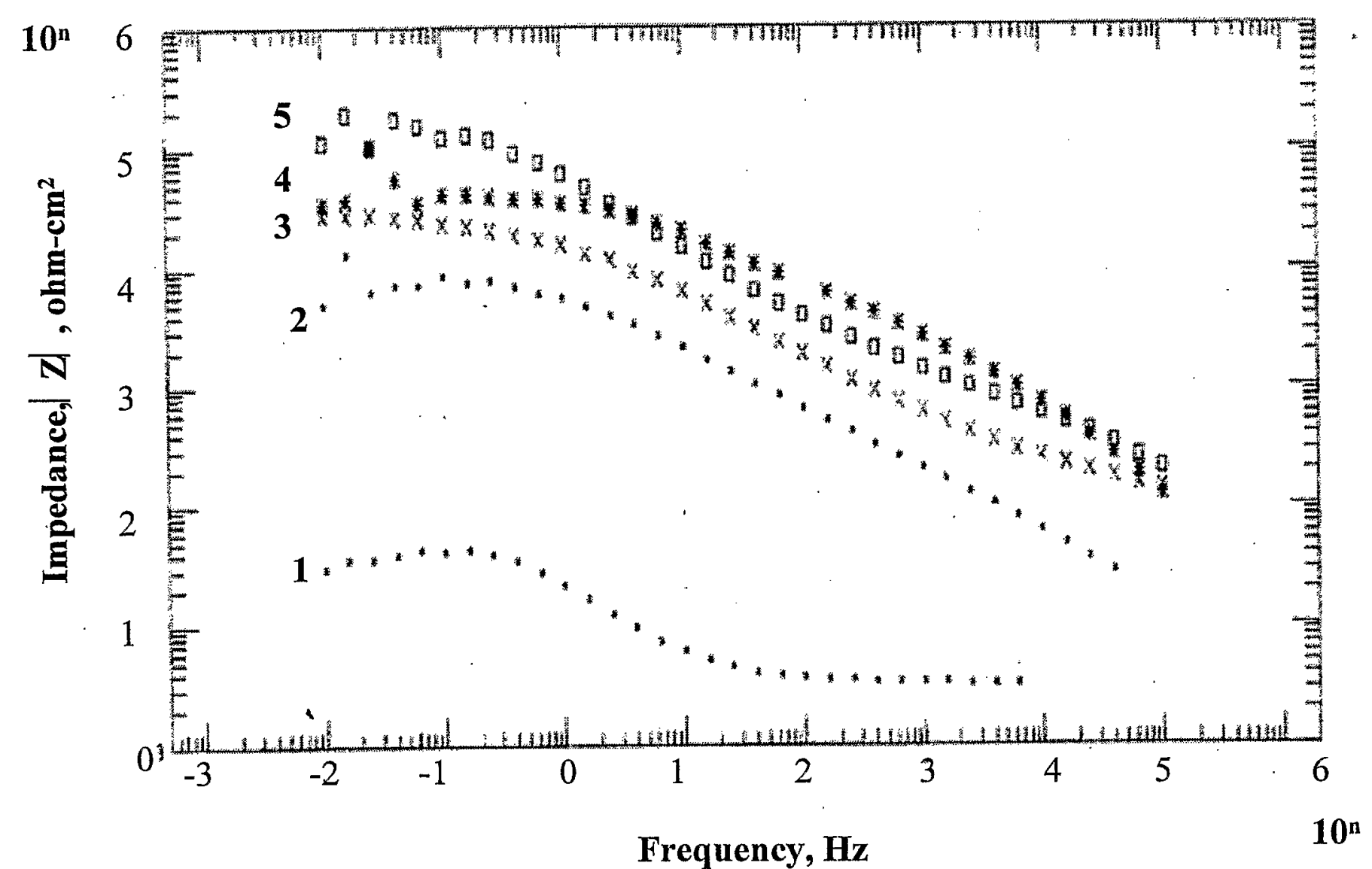

Figure 1. Bode-plot curves of (1) uncoated steel, and (2) 5\% PES-, (3) 20\% PES-, (4) $10 \%$ PES-, and (5) 15 $\%$ PES-coated steels. 


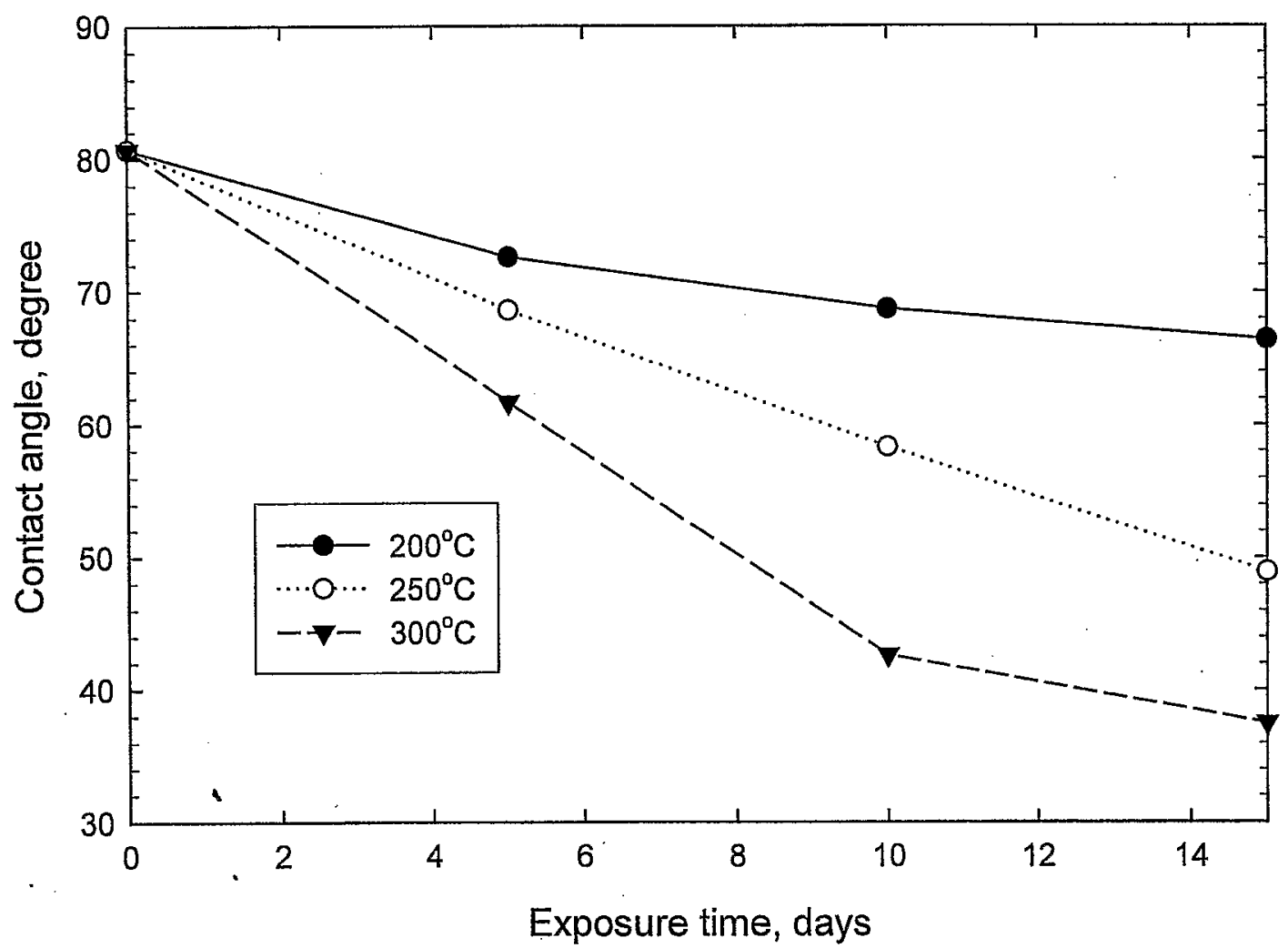

Figure 2. Changes in the contact angle of a water droplet on the $200^{\circ} \mathrm{C}-, 250^{\circ} \mathrm{C}$-, and $300^{\circ} \mathrm{C}$-autoclaved coatings' surfaces as a function of exposure time. 


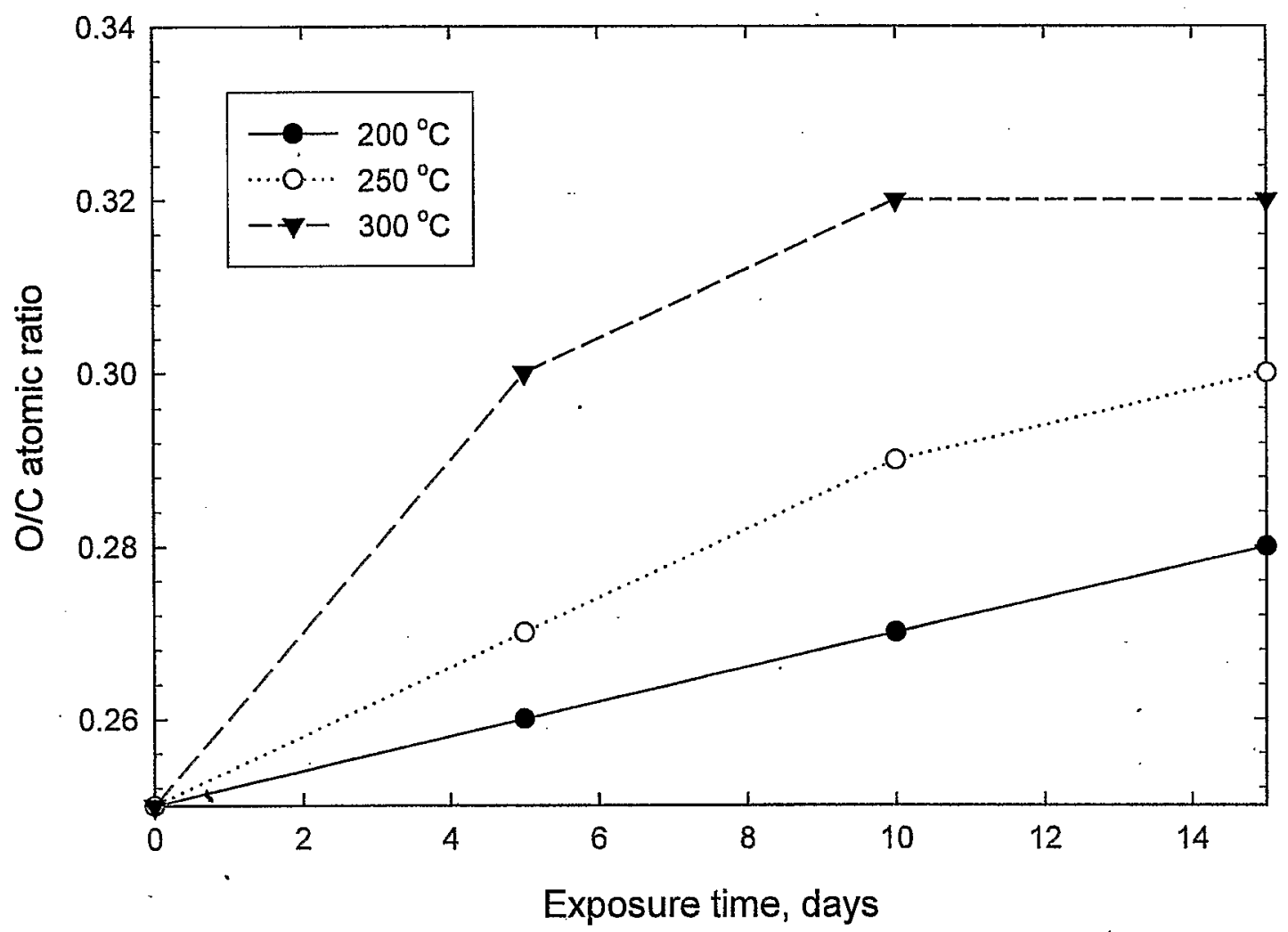

Figure 3. $\mathrm{O} / \mathrm{C}$ atomic ratios plotted against the exposure times for $200^{\circ} \mathrm{C}-, 250^{\circ} \mathrm{C}$-, and $300^{\circ} \mathrm{C}$-autoclaved coatings' surfaces. 

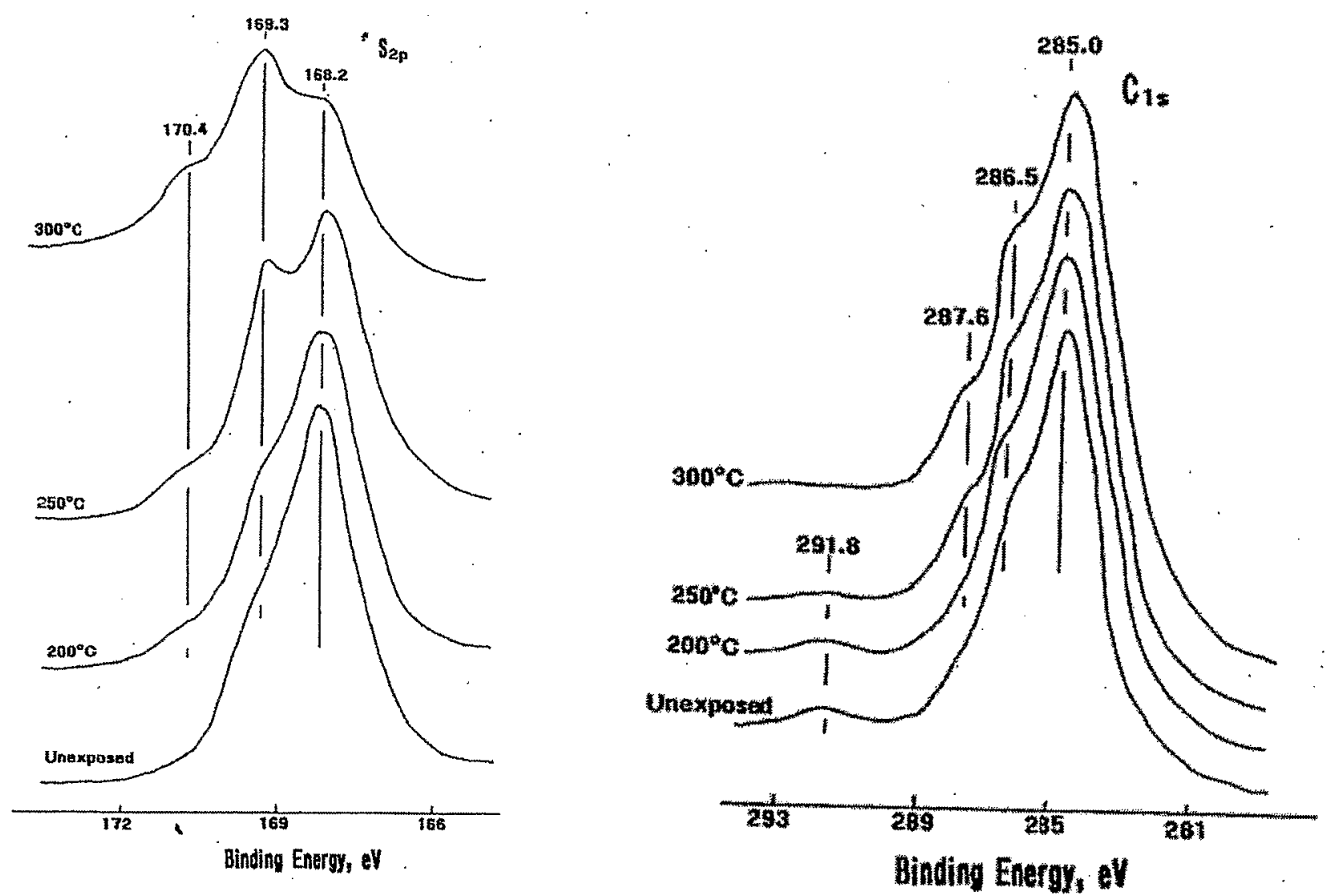

Figure 4. XPS $\mathrm{S}_{2 \mathrm{p}}$ and $\mathrm{C}_{1 \mathrm{~s}}$ regions of unexposed, and $200^{\circ} \mathrm{C}-, 250^{\circ} \mathrm{C}$-, and $300^{\circ} \mathrm{C}$-atuoclaved coatings' surfaces. 


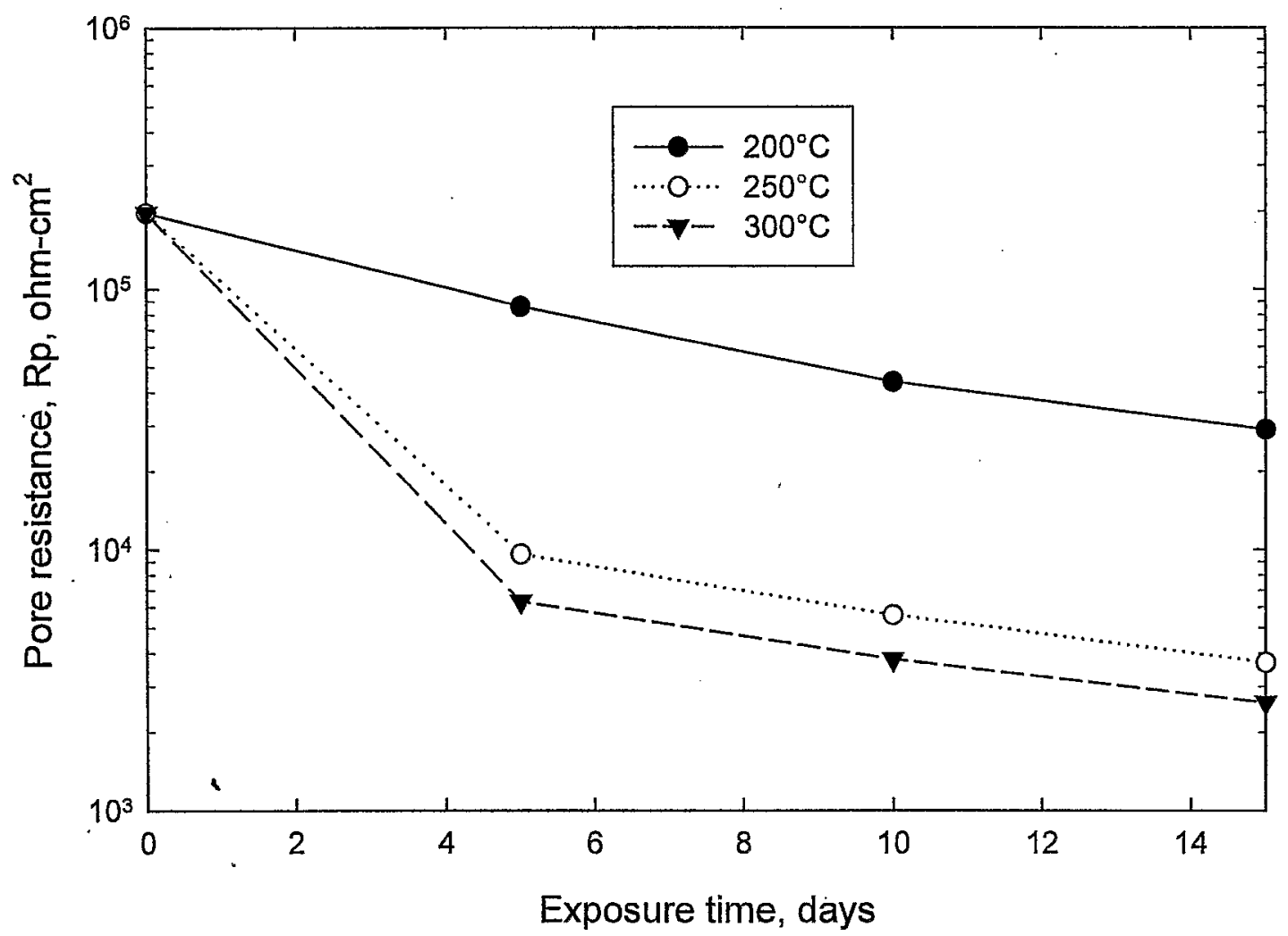

Figure 5. Changes in the pore resistance, $\mathrm{Rp}$, of $200^{\circ} \mathrm{C}-, 250^{\circ} \mathrm{C}$-, and $300^{\circ} \mathrm{C}$-autoclaved coatings as a function of exposure time. 